\title{
A Review Study on Paralympic Games
}

\author{
Dr. SandipSankarGhosh ${ }^{1}$, Miss. SampaBhowmick ${ }^{2}$ \\ Assistant Professors, University of Kalyani, Kalyani, Nadia-741235, West Bengal, India. \\ M.P.Ed student, University of Kalyani, Kalyani, Nadia-741235, West Bengal, India.
}

*Corresponding Author: Dr. SandipSankarGhosh, Assistant Professors, University of Kalyani, Kalyani, Nadia-741235, West Bengal, India

\begin{abstract}
The word "Paralympic" derives from the Greek preposition "para" (beside or alongside) and the word "Olympic". Its meaning is that Paralympics are the parallel Games to the Olympics and illustrates how the two movements exist side-by-side (https://www.paralympic.org). The Paralympic Games is a major international multi sports event involving athletes with a range of disabilities, including impaired muscle power, impaired passive range of movement, limb deficiency, leg length difference, short stature, hypertonia, ataxia, athetosis, vision impairment and intellectual impairment. The first Paralympic Games took place in Rome, Italy in 1960 featuring 400 athletes from 23 countries. Since then they have taken place every four years. As of 2016 summer Paralympic games was included 22 sports and 526 medal events. The IPC has established ten disability categories, including physical, visual, and intellectual impairment. Last Paralympic was held in Rio de Janeiro and upcoming Paralympic games will be held in Tokyo. At 2016 Paralympic India got two gold medals one silver and one bronze medal and squared 43rd rank. In the Present study it was attempted to find out several directions of Paralympic games, its origination and history of development, relationship with Olympic games, several events included according to the degree and types of disability, different group division of Paralympic games, geography of Paralympic games hosted, medal statistics of India in Paralympic games from 1960 to 2016 and the list of the players who had participated in Paralympic and Olympic games simultaneously etc. For that purpose it was reviewed from the origination of this game up to the present status where the tremendous popularity of the games reached in every corner of the globe. The information were collected from various resources and reviewed thoroughly and presented in the present paper.
\end{abstract}

Keywords: Paralympic Games, Olympic Games, Sports, Events

\section{INTRODUCTION}

The Paralympic Games is a major international multi sports event involving athletes with a range of disabilities, including impaired muscle power (e.g. paraplegia and quadriplegia, muscular dystrophy, post-polio syndrome, spina bifida), impaired passive range of movement, limb deficiency (e.g. Amputation or dysmelia), leg length difference, short stature, hypertonia, ataxia, athetosis, vision impairment and intellectual impairment. There are winter and Summer Paralympic Games, which since the 1988 Summer Games in Seoul, South Korea, are held almost immediately following the respective Olympic Games. All Paralympic Games are governed by the International Paralympic Committee (IPC).

The Paralympics has grown from a small gathering of British World War II veterans in 1948 to become one of the largest international sporting events by the early 21 st century. Paralympians strive for equal treatment with non-disabled Olympic athletes, but there is a large funding gap between Olympic and Paralympic athletes.

The Paralympic Games are organized in parallel with the Olympic Games, while the IOC-recognized Special Olympics World Games include athletes with intellectual disabilities, and the Deaflympics include deaf athletes.

Given the wide variety of disabilities that Paralympic athletes have, there are several categories in which the athletes compete. The allowable disabilities are broken down into ten eligible impairment types. The categories are impaired muscle power, impaired passive range of movement, limb deficiency, leg length difference, short stature, hypertonia, ataxia, athetosis, vision impairment and intellectual impairment. These categories are further broken down into classifications, which vary 
from sport to sport. The classification system has led to cheating controversies revolving around athletes who over-stated their disabilities, in addition to the use of performance-enhancing drug

Athletes with disabilities did compete in the Olympic Games prior to the advent of the Paralympics. The first athlete to do so was German American gymnast George Eyser in 1904, which had one artificial leg. Hungarian KarolyTakacs competed in shooting events in both the 1948 and 1952 Summer Olympics. He was a right-arm amputee and could shoot left-handed. Another disabled athlete to appear in the Olympics prior to the Paralympic Games was Lis Hartel, a Danish equestrian athlete who had contracted polio in 1943 and won asilyer medal in the dressage event.

Present study was an attempted to find out several directions of Paralympic games its origination and history of development, relationship with Olympic games, several events included according to the degree and types of disability, different group division of Paralympic games, geography of Paralympic games hosted, medal statistics of India in Paralympic games from 1960 to 2016 and the list of the players who had participated in Paralympic and Olympic games simultaneously etc. For that purpose it was reviewed from the origination of this game up to the present status where the tremendous popularity of the games reached in every corner of the globe. The information were collected from various resources and reviewed thoroughly and presented in the present paper.

\subsection{Relationship with Olympic}

In 2001 the International Olympic Committee (IOC) and the International Paralympic Committee (IPC) signed an agreement which guaranteed that host cities would be contracted to manage both the Olympic and Paralympic Games. This agreement was to remain in effect until the 2012 Summer Olympics but was extended, encompassing all summer and winter games up until the 2020 Summer Olympics.

\section{History OF PARALYMPIC}

Sport for athletes with impairment has existed for more than 100 years, and the first sport clubs for the deaf were already in existence in 1888 in Berlin. It was not until after World War II however, that it was widely introduced. The purpose of it at that time was to assist the large number of war veterans and civilians who had been injured during wartime.

In 1944, at the request of the British Government, Dr. Ludwig Guttmann opened a spinal injuries center at the Stoke Mandeville Hospital in Great Britain, and in time, rehabilitation sport evolved to recreational sport and then to competitive sport. On 29 July 1948, the day of the Opening Ceremony of the London 1948 Olympic Games, Dr. Guttmann organized the first competition for wheelchair athletes which he named the Stoke Mandeville Games, a milestone in Paralympics history. They involved 16 injured servicemen and women who took part in archery. In 1952, Dutch ex-servicemen joined the Movement and the International Stoke Mandeville Games were founded.

These Games later became the Paralympic Games which first took place in Rome, Italy in 1960 featuring 400 athletes from 23 countries. Since then they have taken place every four years. In 1976 the first Winter Games in Paralympics history were held in Sweden, and as with the Summer Games, have taken place every four years. Since the Summer Games of Seoul, Korea in 1988 and the Winter Games in Albertville, France in 1992 the Games have also taken part in the same cities and venues as the Olympics due to an agreement between the IPC and IOC.

Also in 1960, under the aegis of the World Federation of ex-servicemen, an International Working Group on Sport for the Disabled was set up to study the problems of sport for persons with an impairment. It resulted in the creation, in 1964, of the International Sport Organization for the Disabled (IOSD) who offered opportunities for those athletes who could not affiliate to the International Stoke Mandeville Games: visually impaired, amputees, persons with cerebral palsy and paraplegics.

At the start, 16 countries were affiliated to ISOD and the organization pushed very hard to include blind and amputee athletes into the Toronto 1976 Paralympics and athletes with cerebral palsy in 1980 in Arnhem. Its aim was to embrace all impairments in the future and to act as a Co-Coordinating Committee. Nevertheless, other disability-orientated international organizations such as the Cerebral Palsy International Sports and Recreation Association (CPISRA) and International Blind Sports Federation (IBSA) were founded in 1978 and 1980.

The four international organizations experienced the need of coordinating the Games so they created the "International Co-Coordinating Committee Sports for the Disabled in the World" (ICC) in 
1982.The ICC was originally composed of the four presidents of CPISRA, IBSA, ISMGF and ISOD, the general secretaries and one additional member (in the beginning it was the Vice-President, and later on the Technical Officer). The International Committee of Sport for the Deaf (CISS) and International Sports Federations for Persons with an Intellectual Disability (INAS-FID) joined in 1986, but the deaf still maintained their own organization. However, the member nations demanded more national and regional representation in the organization.

Finally, on 22 September 1989, the International Paralympic Committee was founded as an international non-profit organization in Dusseldorf, Germany to act as the global governing body of the Paralympic Movement. The word "Paralympic" derives from the Greek preposition "para" (beside or alongside) and the word "Olympic". Its meaning is that Paralympics are the parallel Games to the Olympics and illustrates how the two movements exists side-by-side.

\section{SPORTS EVENTS AND GaMes OF PARALYMPIC}

The Paralympic sports comprise the sports contested in the summer and winter Paralympic game. As of 2016 summer Paralympic games was included 22 sports and 526 medal events, and the winter Paralympic include 5 sports and disciplines and about 72 events. The number and kind of events may change from one Paralympic games to another.

The Paralympic games are a major international multi-sport event for athletes with physical disability. This includes athletes with mobility, disabilities, amputation, blindness and cerebral palsy. Paralympic sport refers to organized competitive sports activities as part of the global Paralympic movement. These sports are organized and run under the supervision of the international Paralympic committee and other international sports federations.

The name of the sports and games of Paralympic are as follow

\begin{tabular}{|l|l|ll|l|}
\hline$\bullet$ Para-archery & $\bullet$ Para-equestrian & $\bullet$ Power lifting & $\bullet$ Table tennis \\
\hline$\bullet$ Athletics & $\bullet$ Football 5-a-side & $\bullet$ Rowing & $\bullet$ Para triathlon \\
\hline$\bullet$ Bocce & $\bullet$ Football 7-a-side & $\bullet$ Sailing & $\bullet$ Wheelchair fencing \\
\hline$\bullet$ Para-canoe & $\bullet$ Goal ball & $\bullet$ Shooting & $\bullet$ Wheelchair rugby \\
\hline$\bullet$ Cycling & $\bullet$ Judo & $\bullet$ Sitting volleyball & \\
\hline$\bullet$ Swimming & $\bullet$ Wheelchair basketball & $\bullet$ Wheelchair tennis & \\
\hline
\end{tabular}

\section{DIFFERENT GROUP DIVISION OF PARALYMPIC GAMES}

The International Paralympic Committee (IPC) has established ten disability categories. Athletes are divided within each category according to their level of impairment, in a functional classification system which differs from sport to sport. The IPC has established ten disability categories, including physical, visual, and intellectual impairment

\subsection{Physical Impairment}

There are eight different types of physical impairment:

\begin{tabular}{|c|c|}
\hline - $\quad$ Impaired muscle & - $\quad$ Short stature \\
\hline - $\quad$ Impaired passive range of & - $\quad$ Hypertonic \\
\hline - $\quad$ Loss of limb or limb deficiency & - $\quad$ Ataxia \\
\hline - $\quad$ Leg-length difference & - $\quad$ Athetosis \\
\hline
\end{tabular}

\subsection{Visual Impairment}

Athletes with visual impairment ranging from partial vision, sufficient to be judged legally blind, to total blindness. This includes impairment of one or more component of the visual system (eye structure, receptors, optic nerve pathway, and visual cortex).[63] The sighted guides for athletes with a visual impairment are such a close and essential part of the competition that the athlete with visual impairment and the guide are considered a team. Beginning in 2012, these guides (along with sighted goalkeepers in 5-a-side football became eligible to receive medals of their own.

\subsection{Intellectual Disability}

Athletes with a significant impairment in intellectual functioning and associated limitations in adaptive behaviour. The IPC primarily serves athletes with physical disabilities, but the disability group Intellectual Disability has been added to some Paralympic Games. This includes only elite athletes with intellectual disabilities diagnosed before the age of 18. However, the IOC-recognized Special Olympics World Games are open to all people with intellectual disabilities. 


\section{GeOgraphy of PARAlympic}

\begin{tabular}{|l|c|l|c|}
\hline \multicolumn{3}{|c|}{ List of Paralympics host cities } \\
\hline \multicolumn{1}{|c|}{ Summer Paralympic } & \multicolumn{1}{c|}{ Year } & \multicolumn{1}{c|}{ Edition } & \multicolumn{1}{c|}{ Edition } \\
\hline \multicolumn{1}{|c|}{ Year } & I & 1976, Örnsköldsvik & I \\
\hline 1960, Rome & II & 1980, Geilo & II \\
\hline 1964, Tokyo & III & 1984, Innsbruck & III \\
\hline 1968, Tel Aviv & IV & 1988, Innsbruck & IV \\
\hline 1972, Heidelberg & V & 1992, Tignes \& Albertville & VI \\
\hline 1976, Toronto & VI & 1994, Lillehammer & VII \\
\hline 1980, Arnhem, Netherlands & VII & 1998, Nagano & VIII \\
\hline 1984, Stoke Mandeville New York & VIII & 2002, Salt Lake City & IX \\
\hline 1988, Seoul & IX & 2006, Turin & X \\
\hline 1992, Barcelona \& Madrid & X & 2010, Vancouver & XI \\
\hline 1996, Atlanta & XI & 2014, Sochi & XII \\
\hline 2000, Sydney & XII & 2018, PyeongChang & XIII \\
\hline 2004, Athens & XIII & 2022, Beijing & \\
\hline 2008, Beijing & X & & \\
\hline 2012, London & XI & & \\
\hline 2016, Rio de Janeiro & XII & & \\
\hline 2020, Tokyo & XIII & & \\
\hline 2024, Beijing & & & \\
\hline
\end{tabular}

\subsection{India in Paralympic}

An all-time medal table for all Olympic Games from 1896 to 2016, including Summer Olympic Games is as follows

\begin{tabular}{|c|c|c|c|c|c|}
\hline Game & Gold & Silver & Bronze & Total & Rank \\
\hline 1960, Rome & \multicolumn{5}{|c|}{ Did not participate } \\
\hline 1964, Tokyo & \multicolumn{5}{|c|}{ Did not participate } \\
\hline 1968, Tel Aviv & 0 & 0 & 0 & $\mathbf{0}$ & \\
\hline 1972, Heidelberg & 1 & 0 & 0 & 1 & 25 \\
\hline 1976, Toronto & \multicolumn{5}{|c|}{ Did not participate } \\
\hline 1980, Arnhem & \multicolumn{5}{|c|}{ Did not participate } \\
\hline 1984, New York & 0 & 2 & 2 & 4 & 37 \\
\hline 1988, Seoul & 0 & 0 & 0 & $\mathbf{0}$ & \\
\hline 1992, Barcelona & 0 & 0 & 0 & $\mathbf{0}$ & \\
\hline 1996, Atlanta & 0 & 0 & 0 & $\mathbf{0}$ & \\
\hline 2000, Sydney & 0 & 0 & 0 & $\mathbf{0}$ & \\
\hline 2004, Athens & 1 & 0 & 1 & 2 & 53 \\
\hline 2008, Beijing & 0 & 0 & 0 & $\mathbf{0}$ & \\
\hline 2012, London & 0 & 1 & 0 & 1 & 67 \\
\hline 2016, Rio de Janeiro & 2 & 1 & 1 & 4 & 43 \\
\hline Total & 4 & 4 & 4 & 12 & \\
\hline
\end{tabular}

\subsection{Medalist of Paralympic from1960 to 2016}

\begin{tabular}{|c|c|c|c|c|}
\hline Medal & Year & Name/Team & Sport & Event \\
\hline (1) Gold & 1972 & MurlikantPetkar & Swimming & Men's 50m Freestyle 3 \\
\hline \multirow{4}{*}{$\begin{array}{l}\text { (2) Silver } \\
\text { (2) Silver } \\
\text { (3) Bronze } \\
\text { (3) Bronze }\end{array}$} & \multirow{4}{*}{1984} & BhimraoKesarkar & Athletics & Men's Javelin L6 \\
\hline & & Joginder Singh Bedi & Athletics & Men's Shot Put L6 \\
\hline & & Joginder Singh Bedi & Athletics & Men's Javelin L6 \\
\hline & & Joginder Singh Bedi & Athletics & Men's Discus Throw L6 \\
\hline \multirow{2}{*}{$\begin{array}{l}\text { (1) Gold } \\
\text { (3) Bronze }\end{array}$} & \multirow{2}{*}{2004} & DevendraJhajharia & Athletics & Men's Javelin F44/46 \\
\hline & & Rajinder Singh Rahelu & Powerlifting & Men's 56 kg \\
\hline (2) Silver & 2012 & GirishaNagarajegowda & Athletics & Men's High Jump F42 \\
\hline \multirow{4}{*}{$\begin{array}{l}\text { (1) Gold } \\
\text { (1) Gold } \\
\text { (2) Silver } \\
\text { (3) Bronze }\end{array}$} & \multirow{4}{*}{2016} & MariyappanThangavelu & Athletics & Men's High Jump F42 \\
\hline & & DevendraJhajharia & Athletics & Men's Javelin F46 \\
\hline & & Deepa Malik & Athletics & Women's Shot Put F53 \\
\hline & & Ajai Mishra & Athletics & Men’s high jump F42 \\
\hline
\end{tabular}




\subsection{The Name Players who are Participated in Paralympic and Olympic Both}

There have also been other amputee medalists at the Olympic Games prior to the creation of the Paralympics. Oliver Halassy of Hungary, whose left leg was amputated below the knee, won three medals. The names are as follows

\begin{tabular}{|c|c|c|c|c|c|}
\hline \multirow{2}{*}{ Athlete (Nation) } & \multirow{2}{*}{ Impairment } & \multicolumn{2}{|c|}{ Paralympic Games } & \multicolumn{2}{|c|}{ Olympic Games } \\
\hline & & Edition & Sport & \begin{tabular}{|l|} 
Edition \\
\end{tabular} & Sport \\
\hline NeroliFairhall (NZL) & Wheelchair user & 1980,2000 & Sport & Edition & Sport \\
\hline PálSzekeres (HUN) & Wheelchair user & $\begin{array}{l}1992,1996 \\
2000,2004 \\
2008,2012\end{array}$ & Archery & 1984 & Archery \\
\hline Sonia Vettenburg (BEL) & Wheelchair user & 1984,1988 & $\begin{array}{l}\text { Wheelchair } \\
\text { fencing }\end{array}$ & 1988 & Fencing \\
\hline Paola Fantato (ITA) & $\begin{array}{c}\text { Wheelchair user due } \\
\text { to poliomyelitis }\end{array}$ & \begin{tabular}{c|}
1988,1992 \\
1996,20002004
\end{tabular} & Shooting sport & 1992 & $\begin{array}{l}\text { Shooting } \\
\text { sport }\end{array}$ \\
\hline Marla Runyan (USA) & visually impaired & \begin{tabular}{|l|}
1992,1996 \\
\end{tabular} & Archery & 1996 & Archery \\
\hline OrazioFagone (ITA) & leg amputation & \begin{tabular}{|c|} 
2006Turin \\
2010 Vancouver
\end{tabular} & Athletics & $\begin{array}{l}2000 \\
2004\end{array}$ & Athletics \\
\hline Natalia Partyka (POL) & $\begin{array}{c}\text { congenital amputation } \\
\text { of right hand }\end{array}$ & \begin{tabular}{|c|}
2000,2004200, \\
2012
\end{tabular} & Sledge hockey & $|1988,19921994|$ & Short track \\
\hline Natalie du Toit (RSA) & leg amputation & 2004,20082012 & $\begin{array}{l}\text { Para table } \\
\text { tennis }\end{array}$ & 008,20122016 & Table tennis \\
\hline Oscar Pistorius (RSA) & $\begin{array}{l}\text { bilateral below- } \\
\text { knee amputation }\end{array}$ & 2004,20082012 & $\begin{array}{l}\text { Paralympic } \\
\text { swimming }\end{array}$ & 2008 & Swimming \\
\hline AssuntaLegnante (ITA) & visually impaired & 2012,2016 & Athletics & 2012 & Athletics \\
\hline PepoPuch (AUT) & paraplegia & 2012,2016 & Athletics & 2008 & Athletics \\
\hline IlkeWyludda (GER) & leg amputation & 2012 & Equestrian & 2004 Athens & Equestrian \\
\hline Zahra Nemati (IRI) & Wheelchair user & 2012,2016 & Athletics & 1992,19962000 & Athletics \\
\hline Melissa Tapper (AUS) & $\begin{array}{l}\text { Nerve damage in } \\
\text { right arm }\end{array}$ & 2012,2016 & & & \\
\hline Sandra Paović (CRO) & $\begin{array}{l}\text { Paralysis due to } \\
\text { accident }\end{array}$ & 2016 & & & \\
\hline
\end{tabular}

\section{CONCLuSiOnS}

- The Paralympic Games is a major international multi sports event parallel to Olympic Games.

- First Paralympic games took place in Rome, Italy in 1960 featuring 400 athletes from 23 countries.

- India participated in Paralympic Games for the first time in 1968.

- India first owns a medal (Gold) in Paralympic in 1972.

- From 1960 to 2016 India won a total number of 12 medals.

- As of 2016 summer Paralympic games was included 22 sports and 526 medal events.

- The IPC has established ten disability categories, including physical, visual, and intellectual impairment.

- Last Paralympic was held in Rio de Janeiro and upcoming Paralympic games will be held in Tokyo.

- At 2016 Paralympic India got two gold medals one silver and one bronze medal and squared $43^{\text {rd }}$ rank. It was the best rank of India in Paralympic ever.

- First Paralympic medal holder was MurlikantPetkar. And last Paralympic medal holders were MariyappanThangavelu, DevendraJhajharia, Deepa Malik, Ajai Mishra.

\section{REFERENCES}

[1] https://en.m.wikipedia.org

[2] https://www.wired.com

[3] https://www.disabled-world.com

[4] Paralympic.india.org.in 
[5] https://m.paralympic.org

[6] www.mandevillelegacy.org.UK

[7] www.bbc.com

Citation: Dr. SandipSankarGhosh, Miss. SampaBhowmick. "A Review Study on Paralympic Games" International Journal of Sports and Physical Education (IJSPE), vol 4, no. 1, 2018, pp. 19-24. doi:http://dx.doi.org/10.20431/2454-6380.0401005.

Copyright: (C) 2018 Authors. This is an open-access article distributed under the terms of the Creative Commons Attribution License, which permits unrestricted use, distribution, and reproduction in any medium, provided the original author and source are credited. 